\title{
Foundation Giving for \\ Nonprofit and Philanthropic Infrastructure 2004-2012
}

March 2015

Funding for this project was provided by the William and Flora Hewlett Foundation 


\section{About this Project}

The Hewlett Foundation asked Foundation Center to develop a framework for tracking U.S. foundation support globally for nonprofit and philanthropic infrastructure organizations and services, from operating support for nonprofit associations to project support for grantmaker networks to research support for academic institutions studying the sector.

The goals of this undertaking included:

- Documenting how funding is distributed among key organization types in the nonprofit and philanthropic infrastructure field; and

- Tracking how funding for the field has changed over time, both within the nonprofit and philanthropic infrastructure field and compared to U.S. foundation giving overall.

This analysis spans nine years of foundation funding for nonprofit and philanthropic infrastructure from 2004 to 2012, encompassing 717 different funders and 12,200 grants. It could be replicated in the future to continue to track trends over time.

The data set is based on a classification of recipients that receive funding to support the nonprofit and philanthropic infrastructure of the sector, including among them the following types of organizations:

- Grantmaker networks (issue-based, population, regional)

- General management assistance organizations for philanthropic institutions

- Academic centers and research institutions

- Nonprofit and philanthropic information service organizations

- Nonprofit associations

- Public policy/advocacy organizations

For organizations that do many things besides focus on nonprofit and philanthropic infrastructure, only grants related to infrastructure are included in this analysis. 
The classification of recipient organizations broke into two main categories:

1. philanthropy-specific organizations and networks, and

2. other nonprofit infrastructure organizations, networks and services.

The data highlighted in this analysis are based on Foundation Center's annual FC

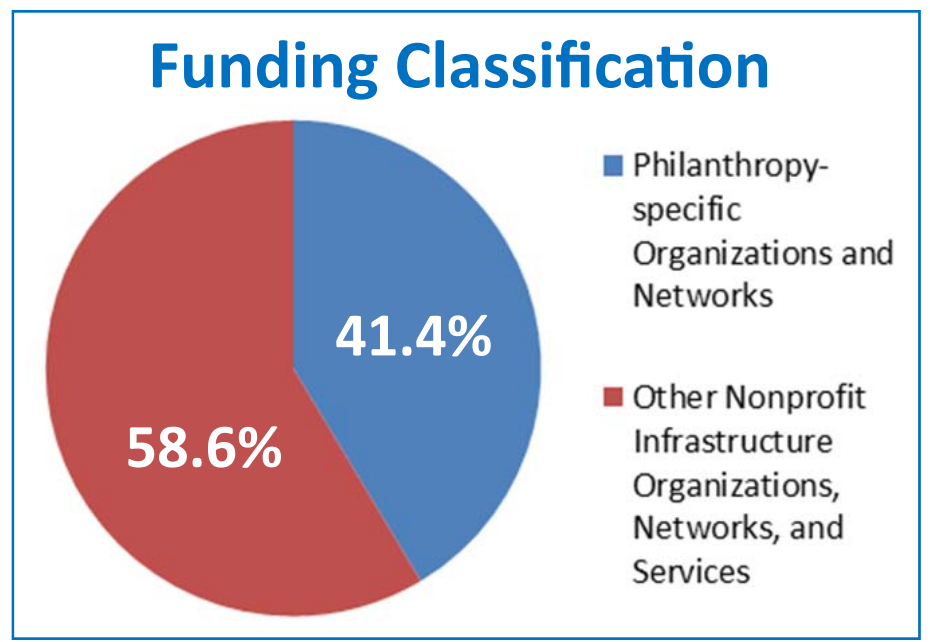
1000 research data set, which accounts for about half of grant dollars awarded by all U.S. foundations each year. These include grants of $\$ 10,000$ or more awarded by 1,000 of the largest U.S. private and community foundations. In this data set, grant amounts are generally reflected in-full in the year the grants were issued.

Not reflected in this analysis is grantmaking for nonprofit and philanthropic infrastructure by the many thousands of foundations not included in the FC 1000 set, as well as grants of less than $\$ 10,000$ made by FC 1000 foundations. While these contributions may not change significantly the overall funding totals reported, their inclusion would result in a substantial increase in the number of foundations that could be identified as having provided funding in this area. At the same time, the share of foundations providing support for nonprofit and philanthropic infrastructure would undoubtedly decline from the 38 percent share report for the FC 1000 set. While grantmaker networks report memberships in the hundreds or even thousands, the vast majority of the more than 87,000 grantmaking U.S. foundations are small foundations unconnected to formal grantmaker networks or other aspects of the nonprofit and philanthropic infrastructure.

This document illustrates key findings from this research and analysis.

Copyright (C 2015 Foundation Center. This work is made available under the terms of the Creative Commons Attribution-NonCommercial 4.0 Unported License, creativecommons.org/ licenses/by-nc/4.0/. 


\section{How much foundation funding supports}

\section{nonprofit and philanthropic infrastructure}

organizations, networks, and services?

\section{KEY FINDINGS:}

- U.S. foundation support for nonprofit and philanthropic infrastructure totaled more than \$1 billion between 2004 and 2012, based on giving by 1,000 of the country's largest foundations.

- Philanthropy-specific organizations and networks captured less than half of grant dollars (41\%) but over half of the number of grants awarded (52\%). 


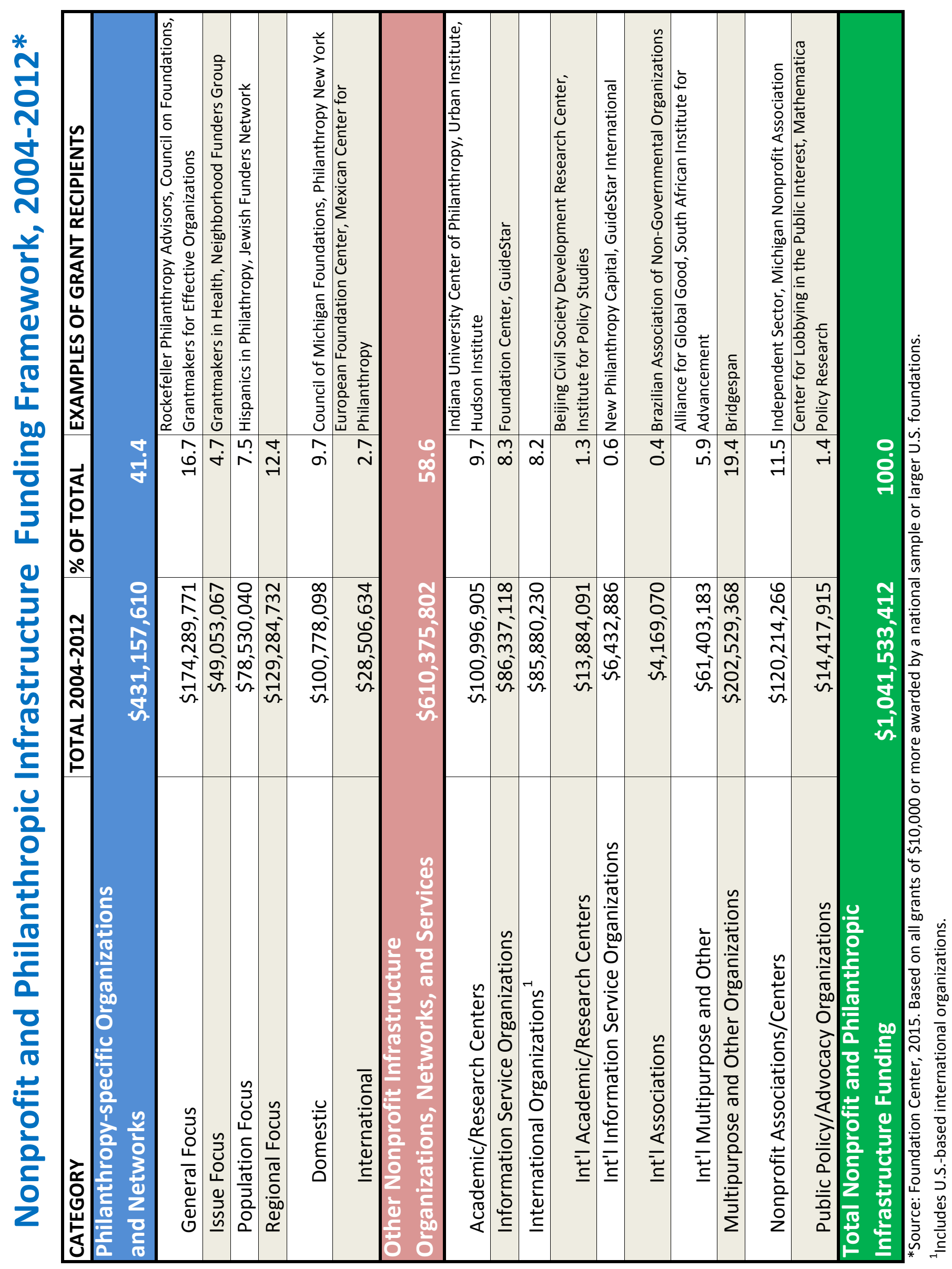




\section{Is funding for infrastructure growing?}

Funding for Nonprofit and Philanthropic Infrastructure, 2004-2012*

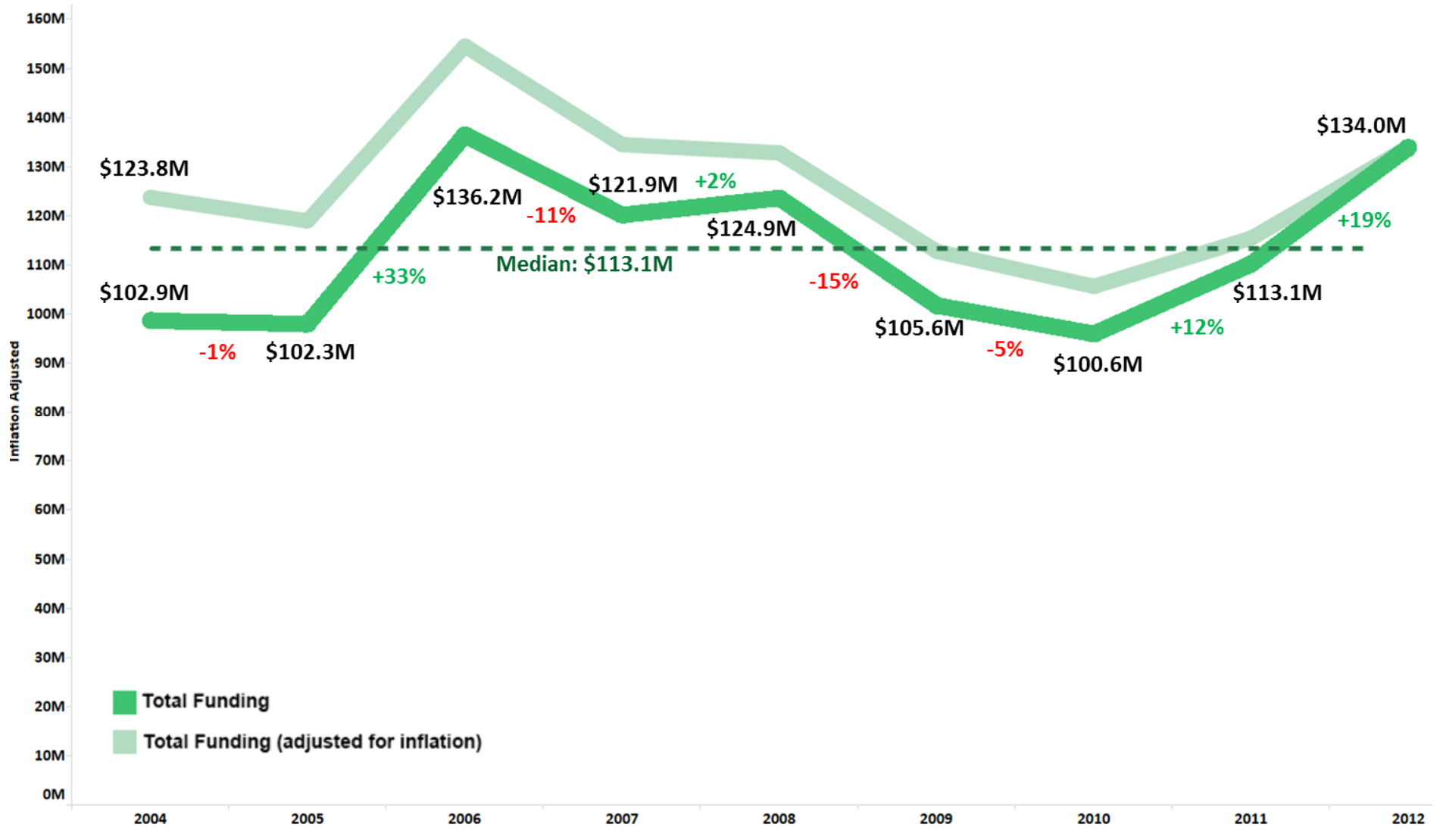

\section{KEY FINDINGS:}

- U.S. foundation funding for nonprofit and philanthropic infrastructure grew $30 \%$ between 2004 and 2012, despite a dramatic drop in funding following the onset of the Great Recession in 2008 and 2009.

- Adjusted for inflation, infrastructure giving by FC 1000 foundations rose $8 \%$ during this period.

*Source: Foundation Center, 2015. Based on all grants of $\$ 10,000$ or more awarded by a national sample of larger U.S. foundations. 


\section{How has support for infrastructure fared relative to overall foundation giving?}

Change in Nonprofit and Philanthropic Infrastructure and Overall U.S. Foundation Funding Between 2004 and 2012*

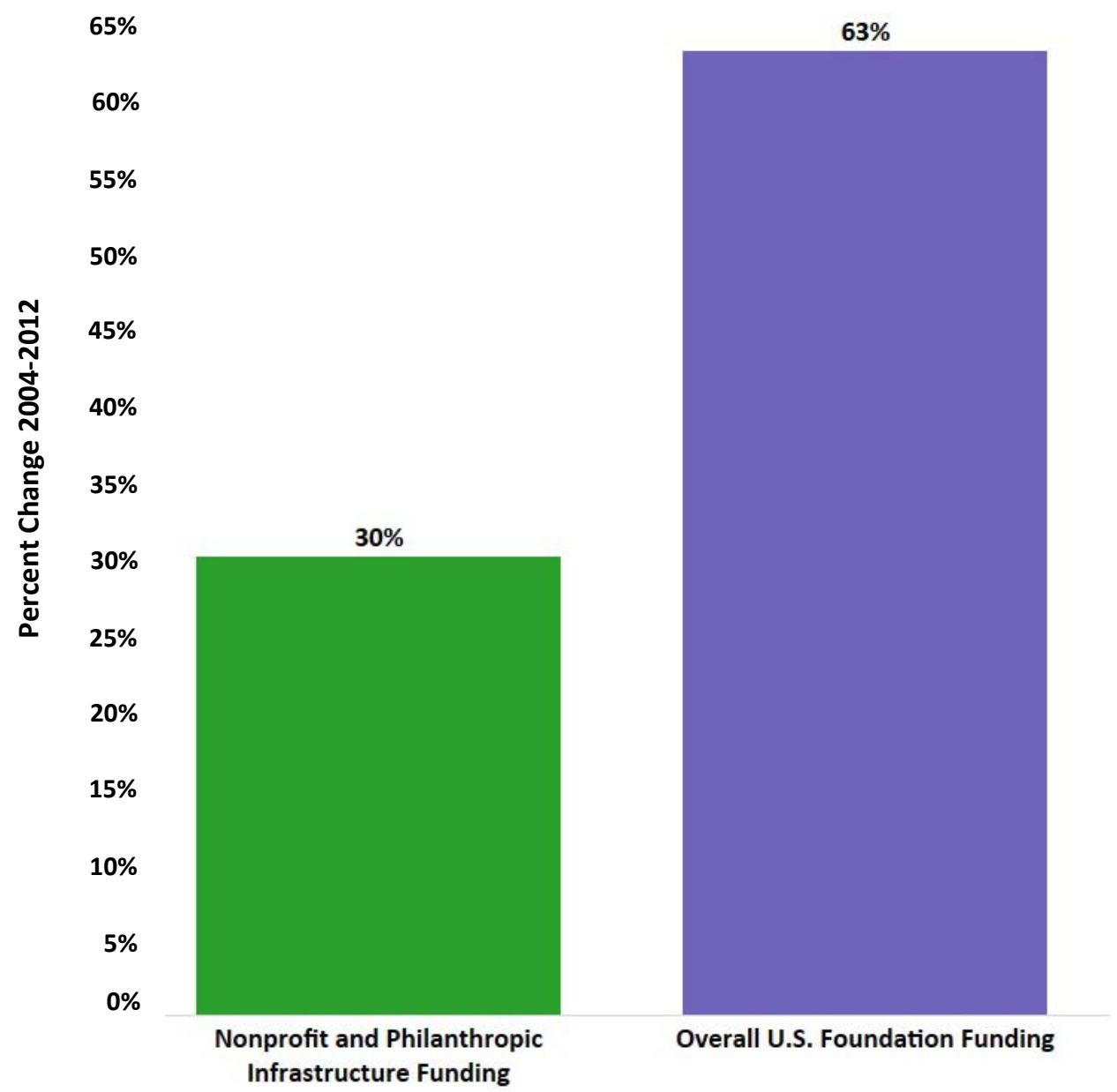

\section{KEY FINDINGS:}

- The increase in infrastructure funding did not keep pace with overall giving by U.S. foundations, which grew roughly twice as fast during this period (+63\% before inflation).

- Infrastructure funding also lagged relative to growth in nonprofit revenues between 2004 and 2012 (+59\% before inflation).

*Source: Foundation Center, 2015. Based on all grants of $\$ 10,000$ or more awarded by a national sample of larger U.S. foundations. 


\section{Funding for Nonprofit and Philanthropic Infrastructure as a Share of Overall Foundation Giving, 2004-2012*}

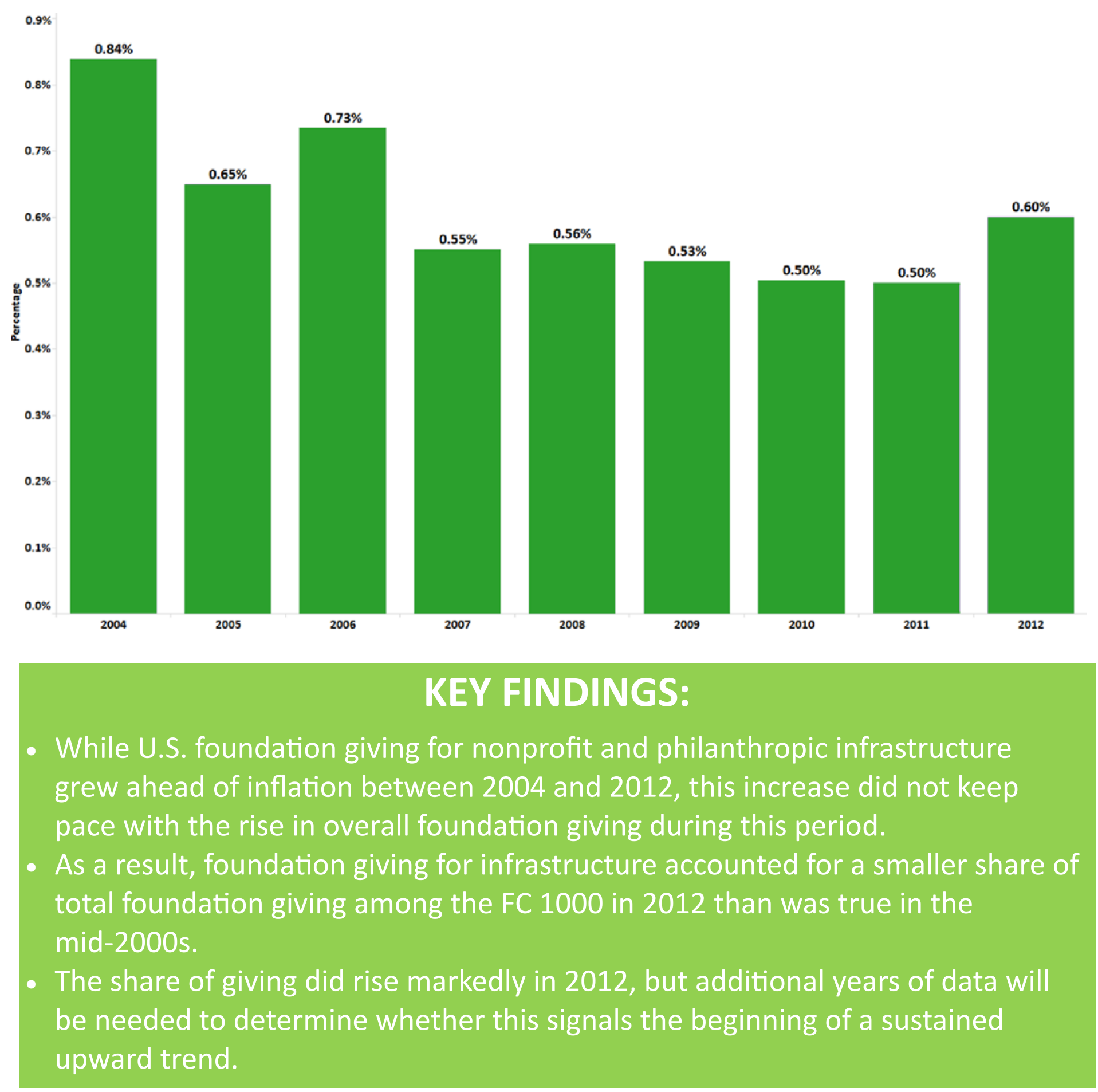

*Source: Foundation Center, 2015. Based on all grants of $\$ 10,000$ or more awarded by a national sample of larger U.S. foundations. 


\section{How did funding compare between types of organizations from 2004-2012?}

\section{Funding for Philanthropy-specific Organizations and Networks and Other Nonprofit Infrastructure Organizations, 2004-2012*}

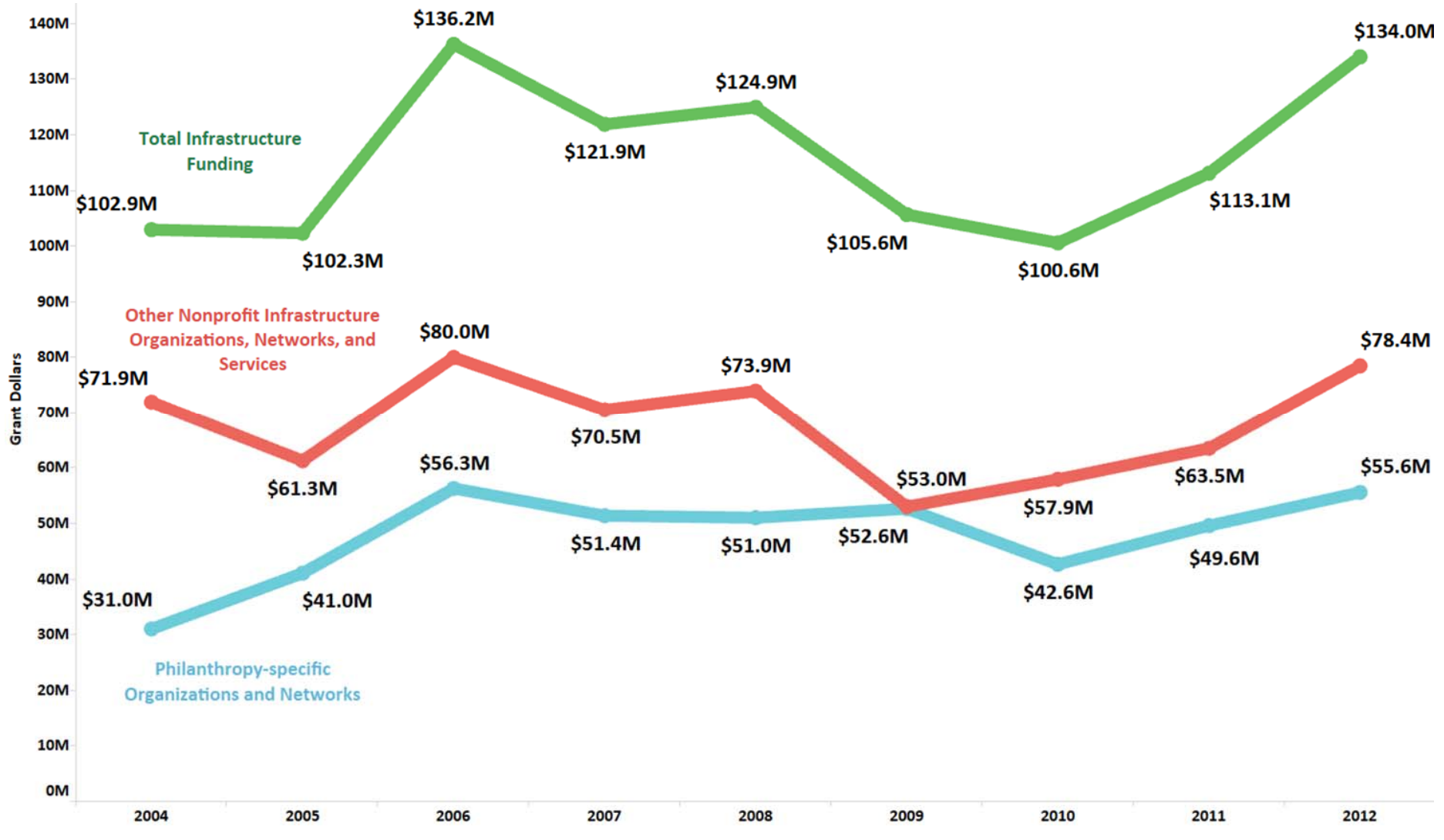

\section{KEY FINDINGS:}

- Other nonprofit infrastructure organizations, networks, and services experienced a marked drop in funding immediately following the Great Recession, while giving for philanthropy-specific organizations and networks grew slightly.

- This finding suggests that foundations funding infrastructure focused on shoring up the organizations with which they were most directly engaged-in this case, grantmaker networks.

- Philanthropy-specific networks have also experienced much stronger overall growth in funding during this period ( $+79 \%$ before inflation) relative to other nonprofit infrastructure organizations, networks, and services (+9\% before inflation).

*Source: Foundation Center, 2015. Based on all grants of $\$ 10,000$ or more awarded by a national sample of larger U.S. foundations. 


\section{Has the median grant size increased?}

\section{Median Grant Sizes for Nonprofit and Philanthropic Infrastructure, 2004-2012*}

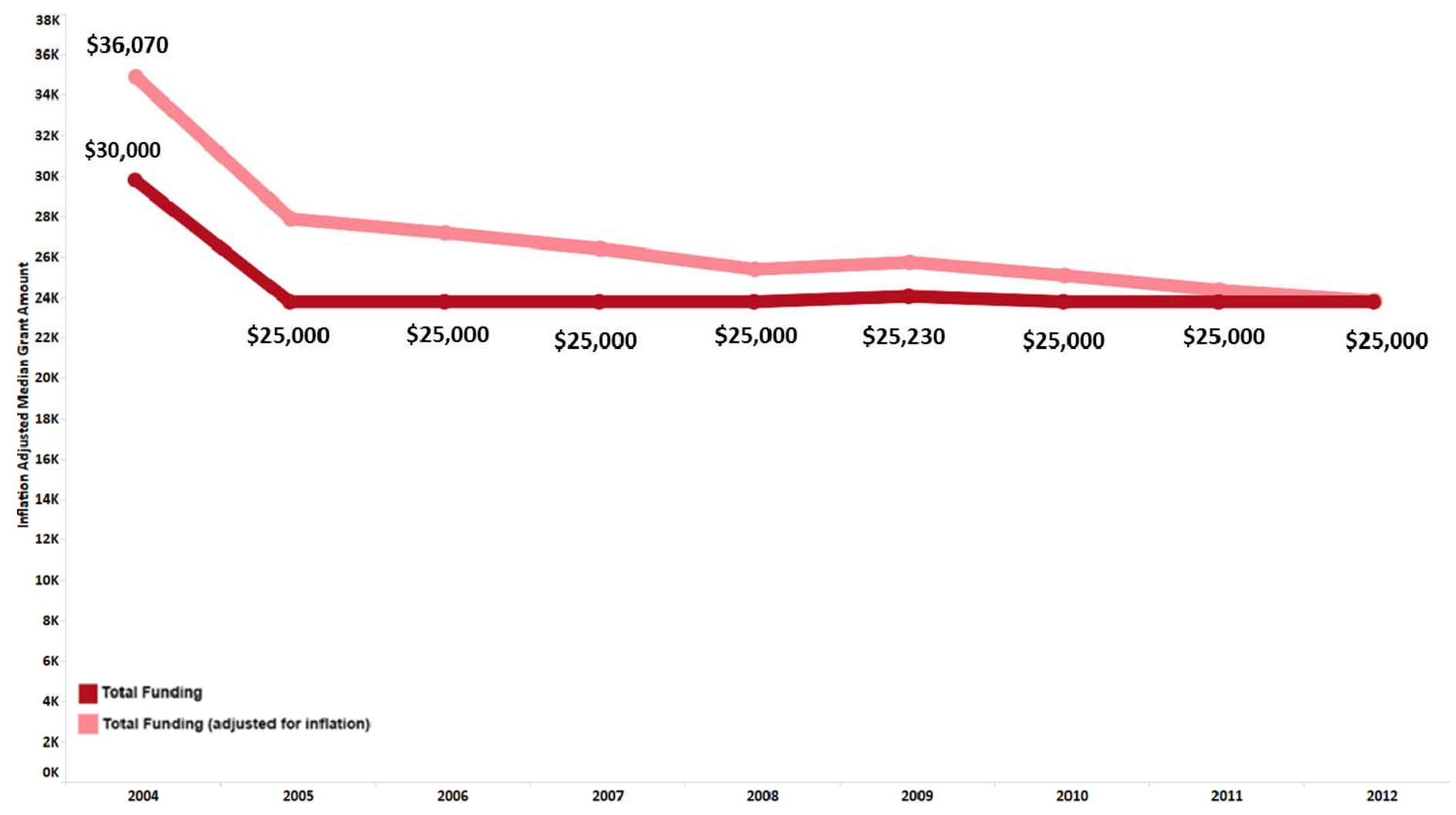

\section{KEY FINDINGS:}

- Excluding 2004, the current-dollar value of the median U.S. foundation grant for nonprofit and philanthropic infrastructure has remained nearly unchanged through 2012.

- Nonetheless, the value of the median grant has declined after adjusting for inflation, suggesting that the typical infrastructure grant now has less purchasing power than was true in 2004.

- Infrastructure grants of $\$ 25,000$ or under accounted for at least half of all grants in 2012, but less than $10 \%$ of total dollars awarded that year. This means that fewer, larger grants comprised the majority of total infrastructure funding.

*Source: Foundation Center, 2015. Based on all grants of $\$ 10,000$ or more awarded by a national sample of larger U.S. foundations. 


\section{How concentrated is infrastructure giving among the leading funders?}

\section{Number of Foundations Funding Infrastructure, 2004-2012*}

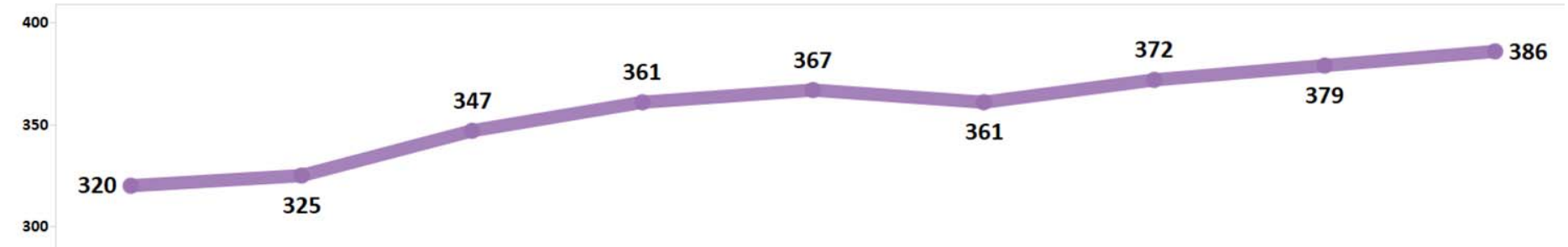

250

150

100

50

0

\section{KEY FINDINGS:}

- The number of U.S. foundations in the FC 1000 set providing at least one nonprofit or philanthropic infrastructure-related grant has grown $21 \%$ to almost two out of five as of 2012.

- Over the same period, however, the total number of U.S. foundations climbed by $27 \%$.

- This means that 386 of 1,000 foundations, or $38.6 \%$ of funders included in this analysis, provide support for philanthropic and nonprofit infrastructure. As noted in the introduction, however, there are likely many more (hundreds or even thousands of) foundations making small contributions to support philanthropic and nonprofit infrastructure that are not captured in the FC 1000 data set.

*Source: Foundation Center, 2015. Based on all grants of $\$ 10,000$ or more awarded by a national sample of larger U.S. foundations. 


\section{Top 5, Top 15, and Other Foundation Infrastructure}

\section{Funders Ranked by Giving*}
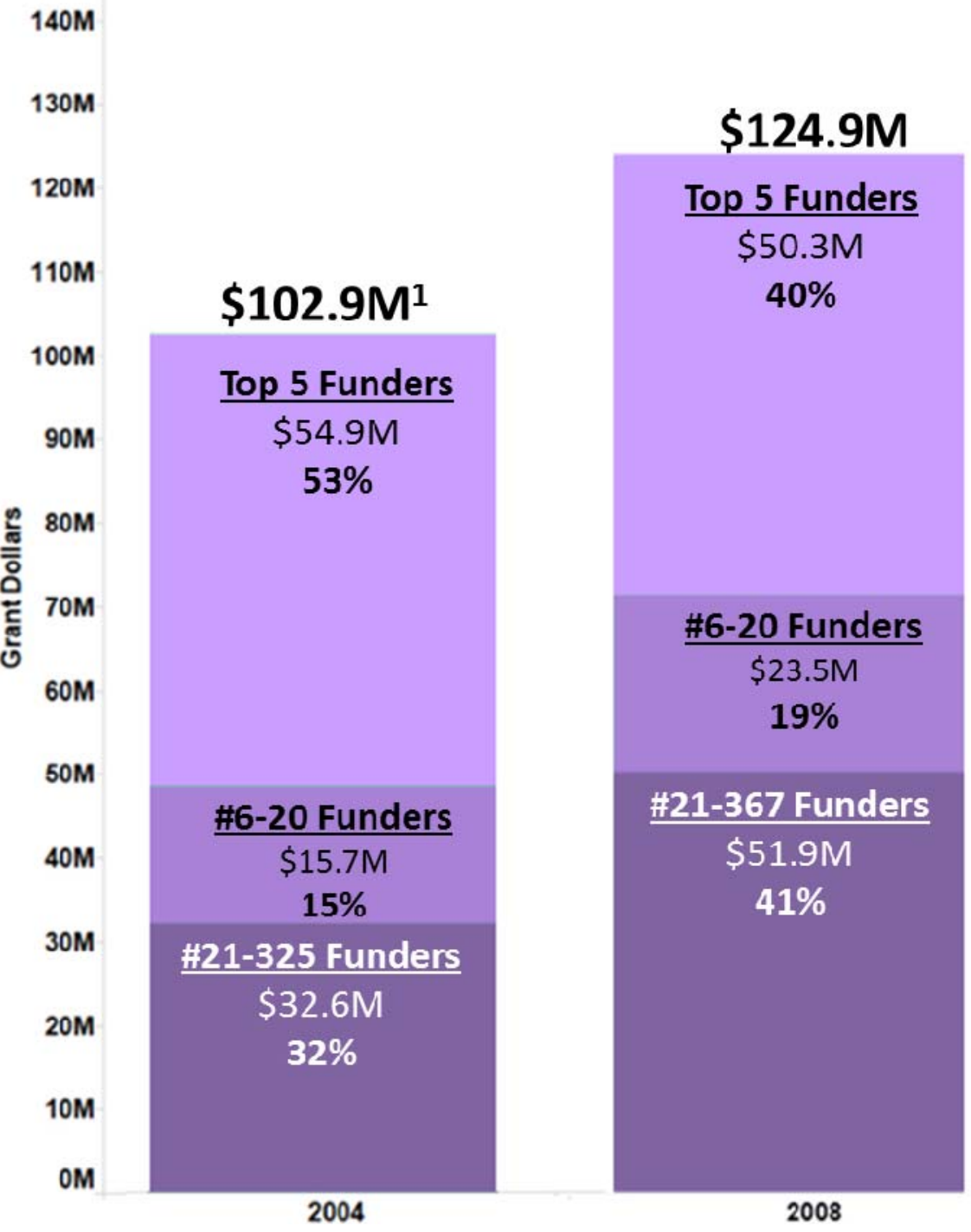

\section{\$134M}

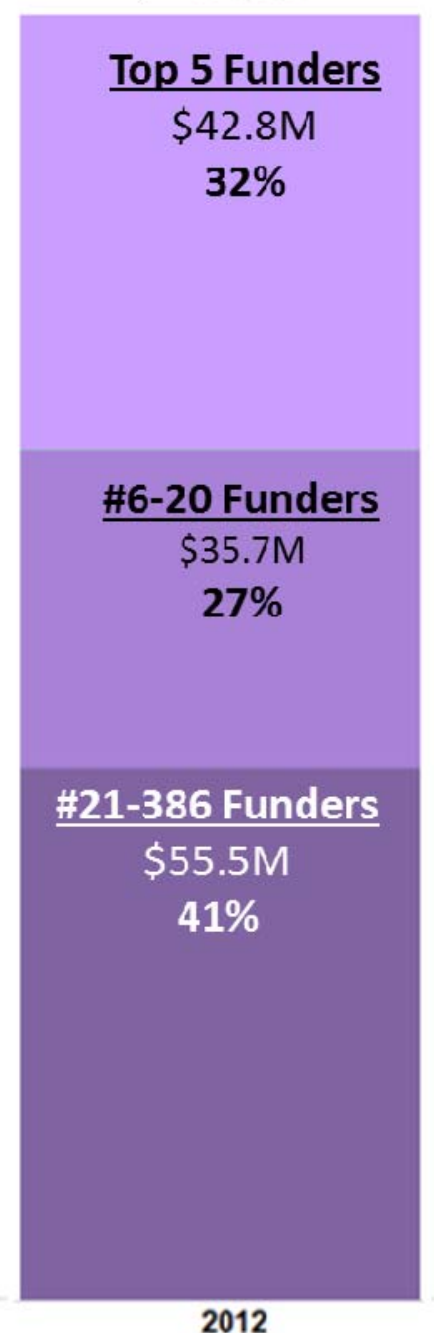

\section{KEY FINDINGS:}

- While a small number of foundations continue to account for a substantial share of U.S. foundation giving for nonprofit and philanthropic infrastructure, this share declined between 2004 and 2012.

- This suggests that a greater number of foundations are making a stronger commitment to supporting the infrastructure of the sector.

- As noted, there are likely many more (hundreds or even thousands of) foundations making small contributions to support philanthropic and nonprofit infrastructure that are not captured in the FC 1000 data set.

*Source: Foundation Center, 2015. Based on all grants of $\$ 10,000$ or more awarded by a national sample of larger U.S. foundations. 


\section{Top 20 Foundations Funding Infrastructure, 2004-2012*}

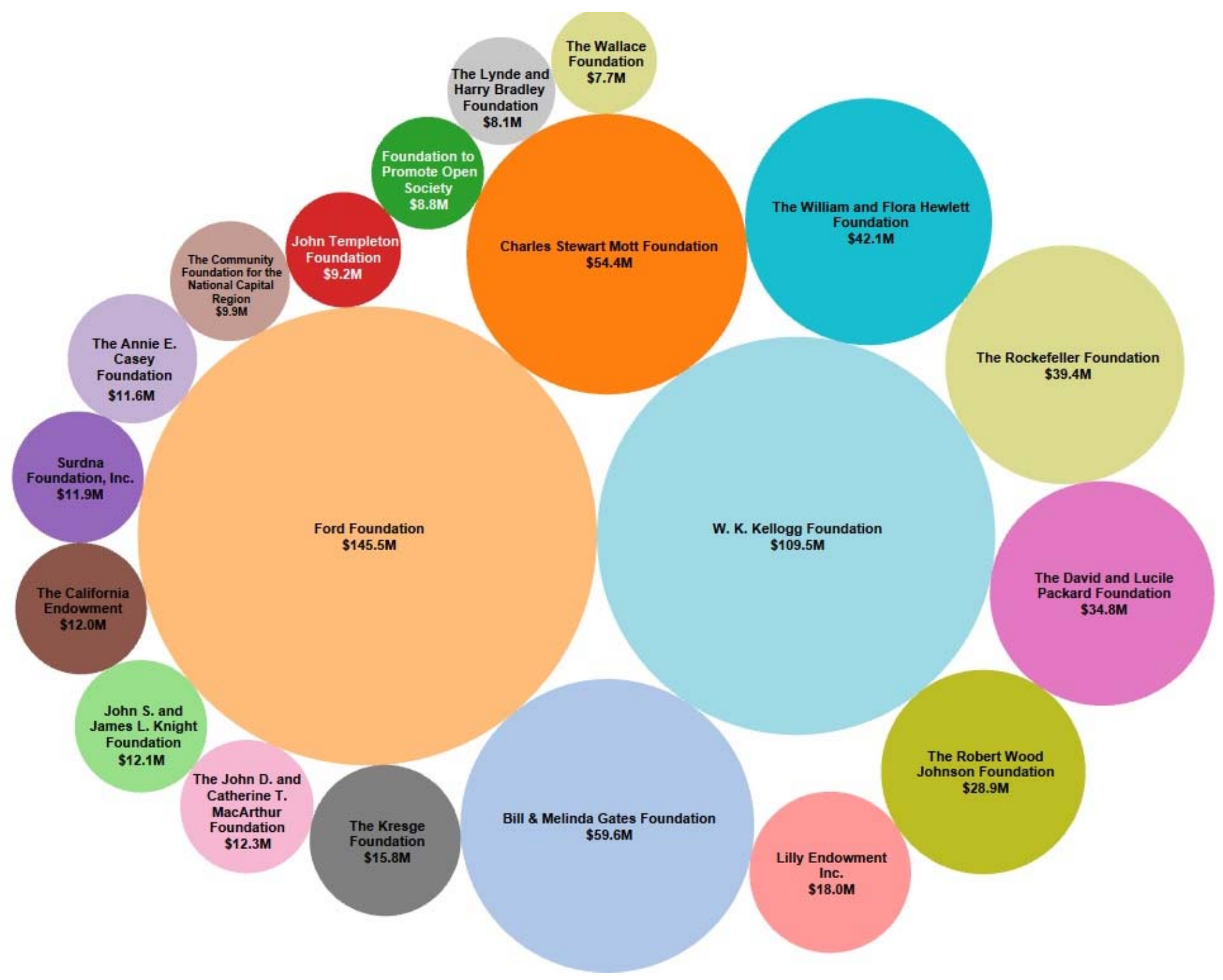

\section{KEY FINDINGS:}

- The New York-based Ford Foundation and Michigan-based W.K. Kellogg Foundation ranked as the largest funders of nonprofit and philanthropic infrastructure between 2004 and 2012.

- Together, the top 20 funders gave $\$ 652$ million or $63 \%$ of the more than $\$ 1$ billion supporting the field during this period.

*Source: Foundation Center, 2015. Based on all grants of $\$ 10,000$ or more awarded by a national sample of larger U.S. foundations. 


\section{How concentrated is infrastructure giving among the leading recipients?}

\section{Number of Recipients Receiving Infrastructure Funding, 2004-2012*}

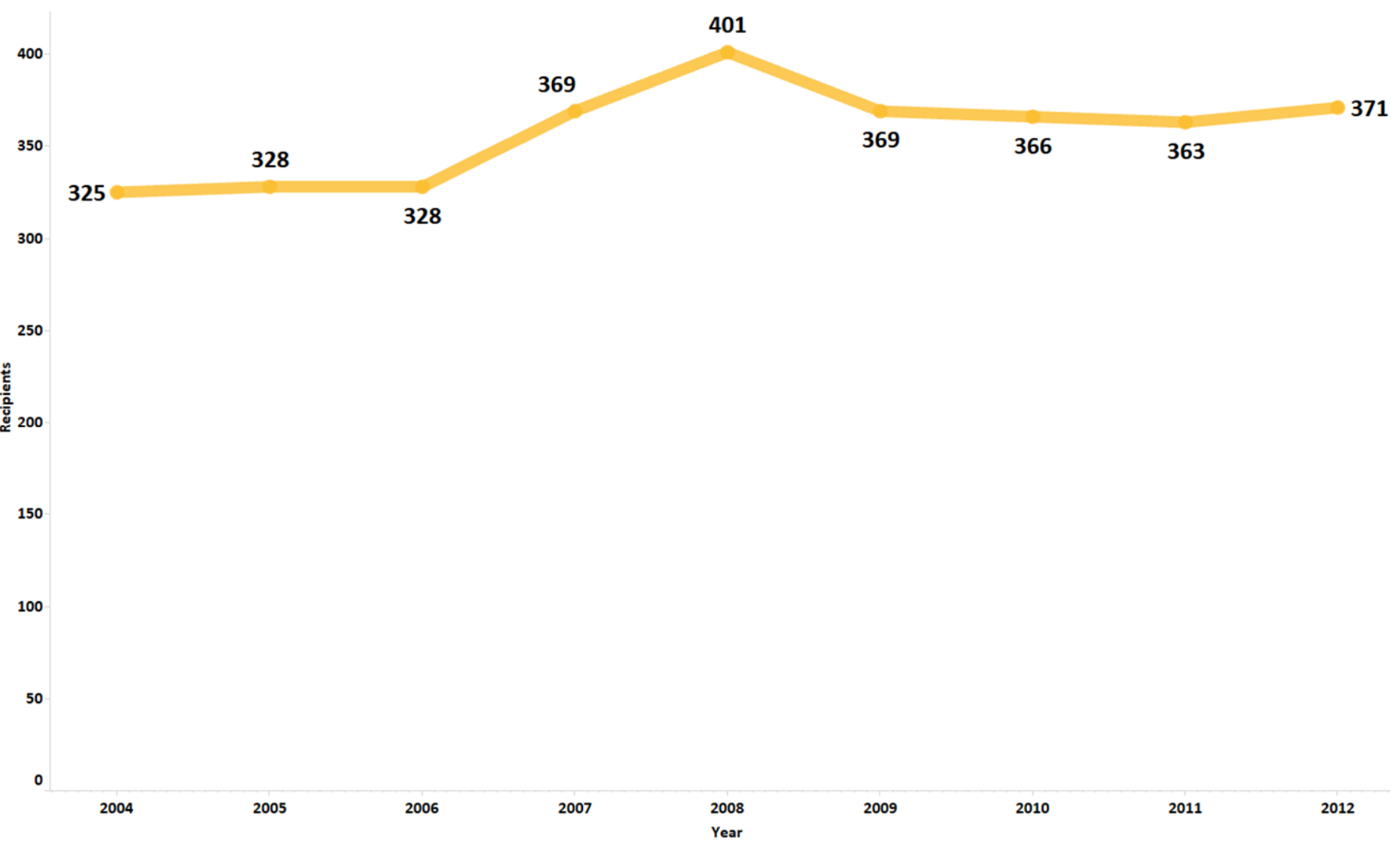

\section{KEY FINDINGS:}

- U.S. foundation support for nonprofit and philanthropic infrastructure is being distributed more broadly.

- The number of unique organizations receiving U.S. foundation funding related to infrastructure has grown 14\% between 2004 and 2012.

- However, the total number of recipients reported for 2012 remains below the peak number recorded for 2008.

*Source: Foundation Center, 2015. Based on all grants of $\$ 10,000$ or more awarded by a national sample of larger U.S. foundations. 


\section{Top 5, Top 15, and Other Recipients of Foundation Infrastructure Funding Ranked by Giving*}

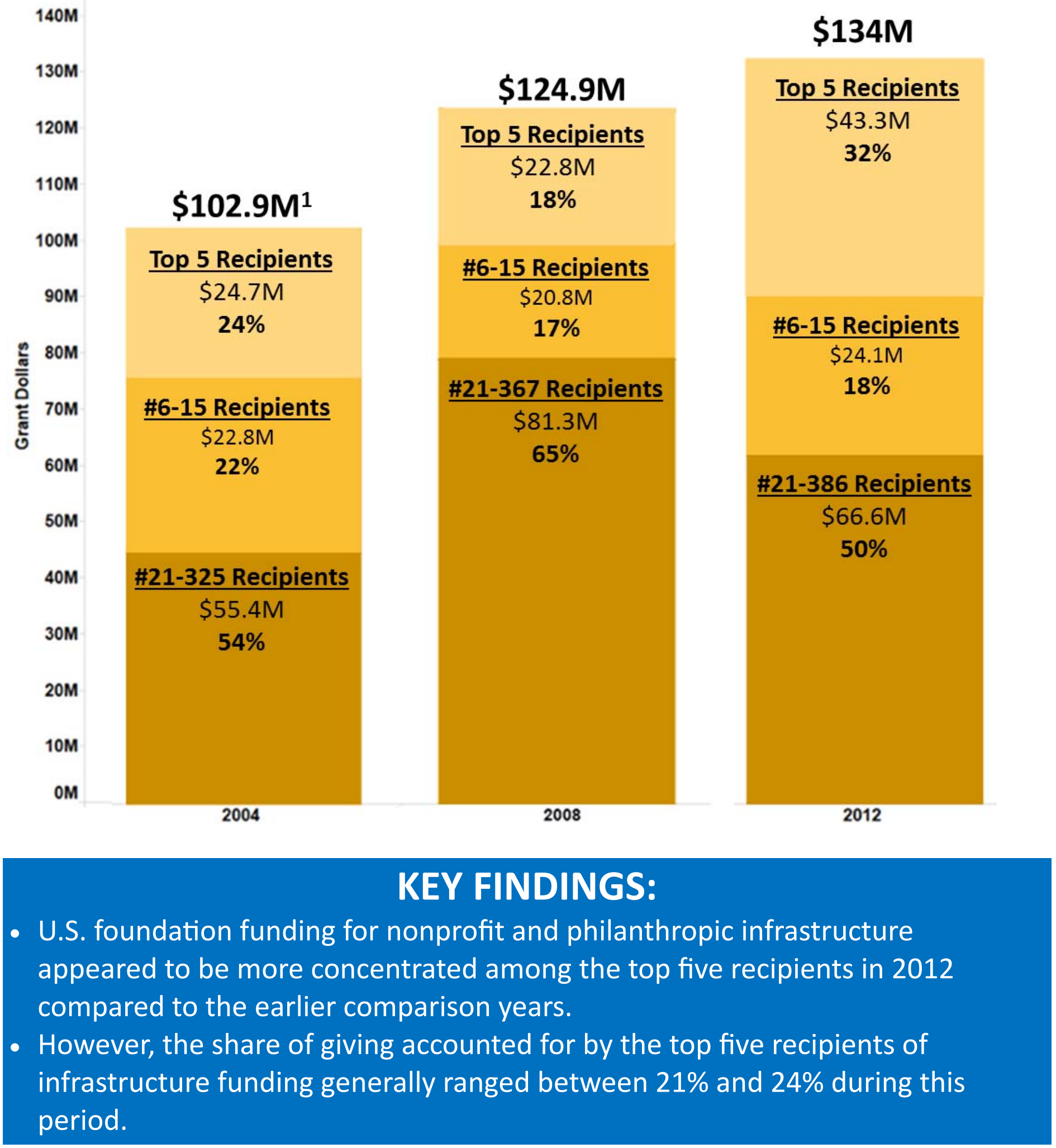

*Source: Foundation Center, 2015. Based on all grants of $\$ 10,000$ or more awarded by a national sample of larger U.S. foundations. 


\section{Top 20 Recipients of Infrastructure Funding, 2004-2012*}

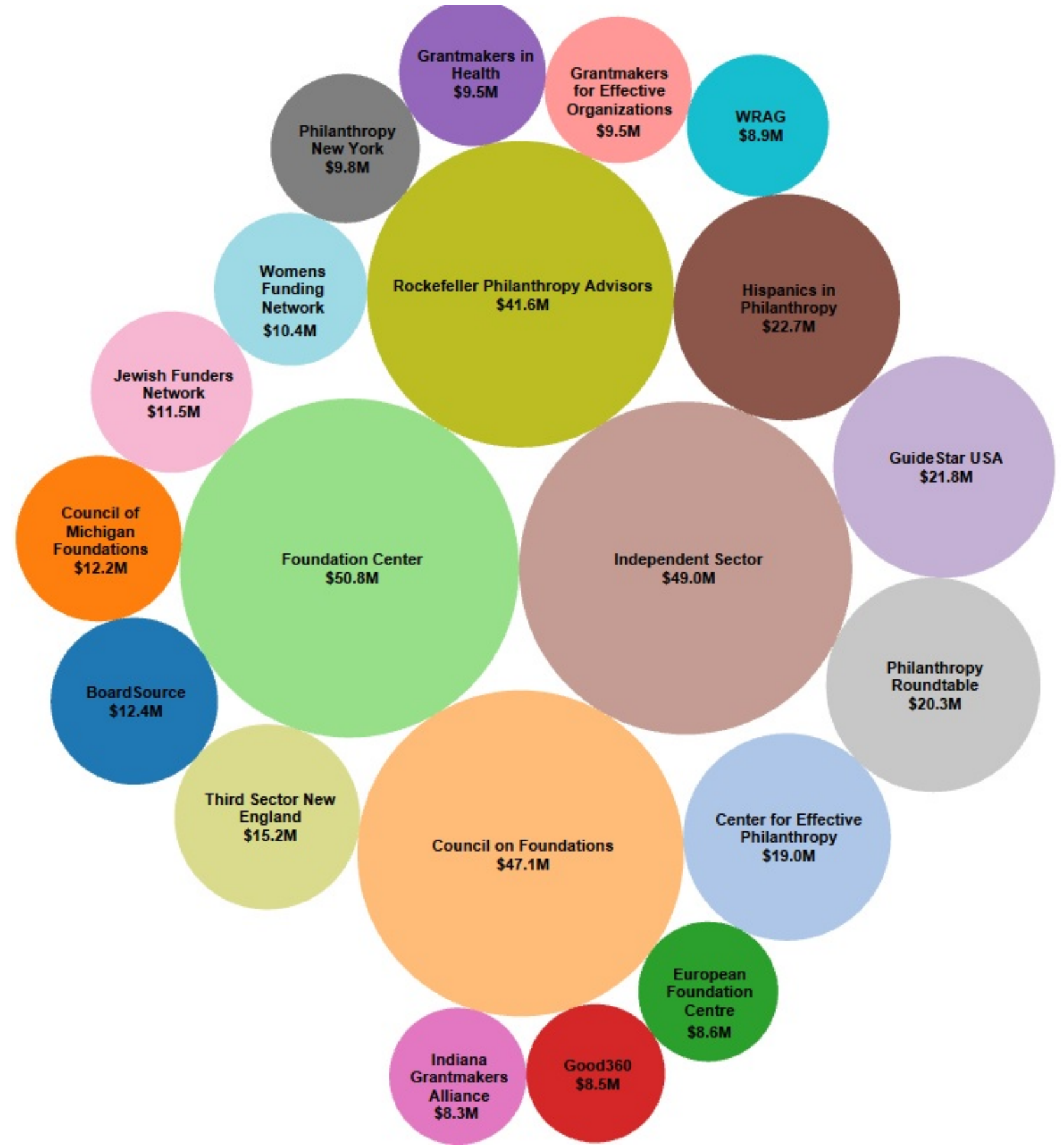

\section{KEY FINDINGS:}

- Four organizations-Foundation Center, Independent Sector, Council on Foundations, and Rockefeller Philanthropy Advisors - captured \$188.6 million, close to one-fifth of total U.S. foundation funding for nonprofit and philanthropic infrastructure between 2004 and 2012.

- Overall, the top 20 recipients organizations received $38 \%$ of total funding reported by all 1,158 unique organizations receiving infrastructure grants during this period.

*Source: Foundation Center, 2015. Based on all grants of $\$ 10,000$ or more awarded by a national sample of larger U.S. foundations. 


\section{Which types of infrastructure organizations have benefitted from the most growth in funding?}

Change in Funding for Philanthropy-specific Organizations and Networks between 2004 and 2012*

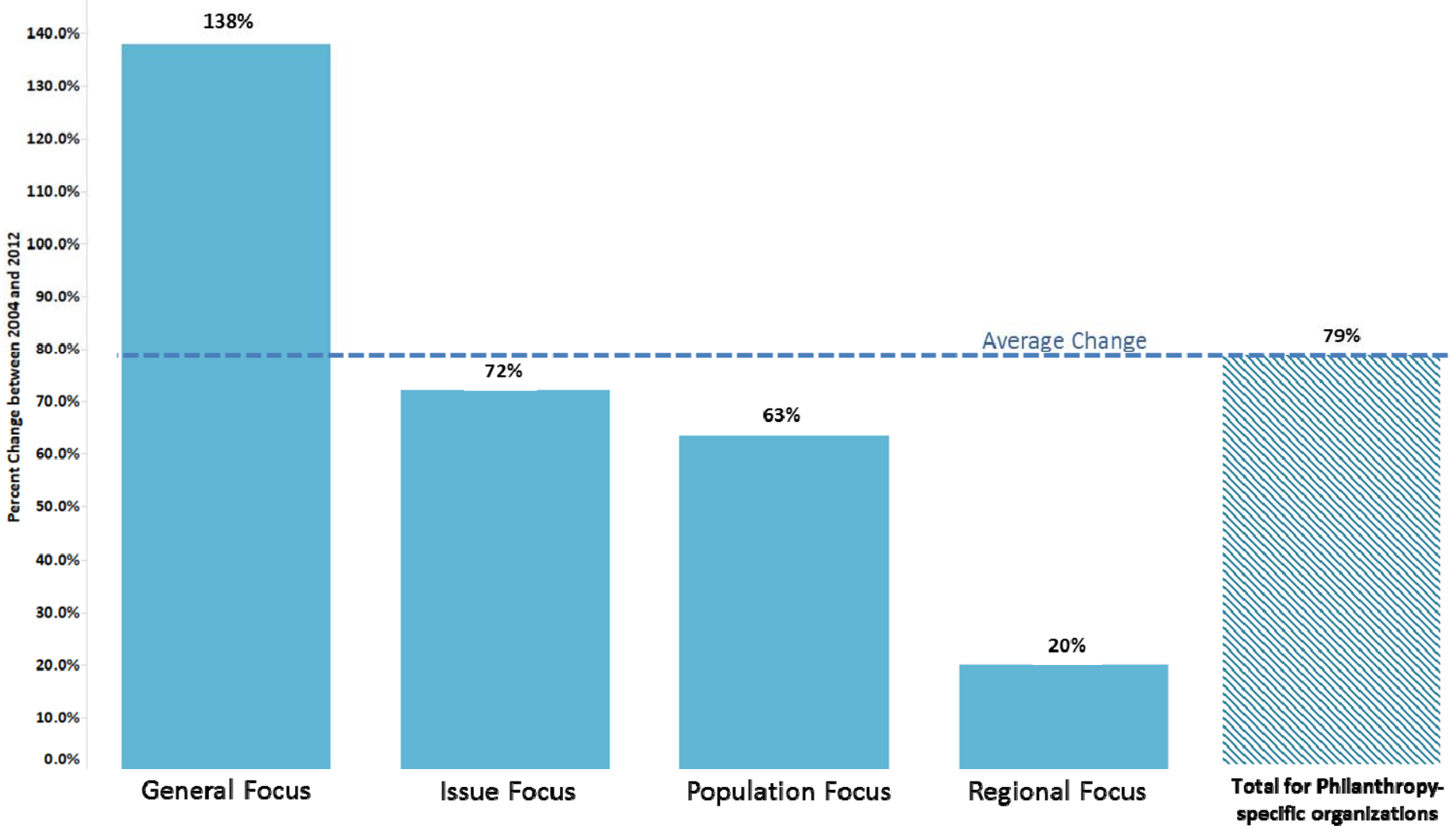

\section{KEY FINDINGS:}

- Among philanthropy-specific organizations and networks, general focus organizations (e.g., Rockefeller Philanthropy Advisors and Council on Foundations) benefited from the largest growth in grant dollars between 2004 and 2012 , by far.

- By comparison, regionally-focused grantmaker networks reported growth in infrastructure giving that was about one-quarter the rate of the overall increase.

- For examples of organizations in each category, see framework on page 5.

*Source: Foundation Center, 2015. Based on all grants of $\$ 10,000$ or more awarded by a national sample of larger U.S. foundations. 


\section{Top 20 Recipients: Philanthropy-specific Organizations and}

\section{Networks, 2004-2012*}

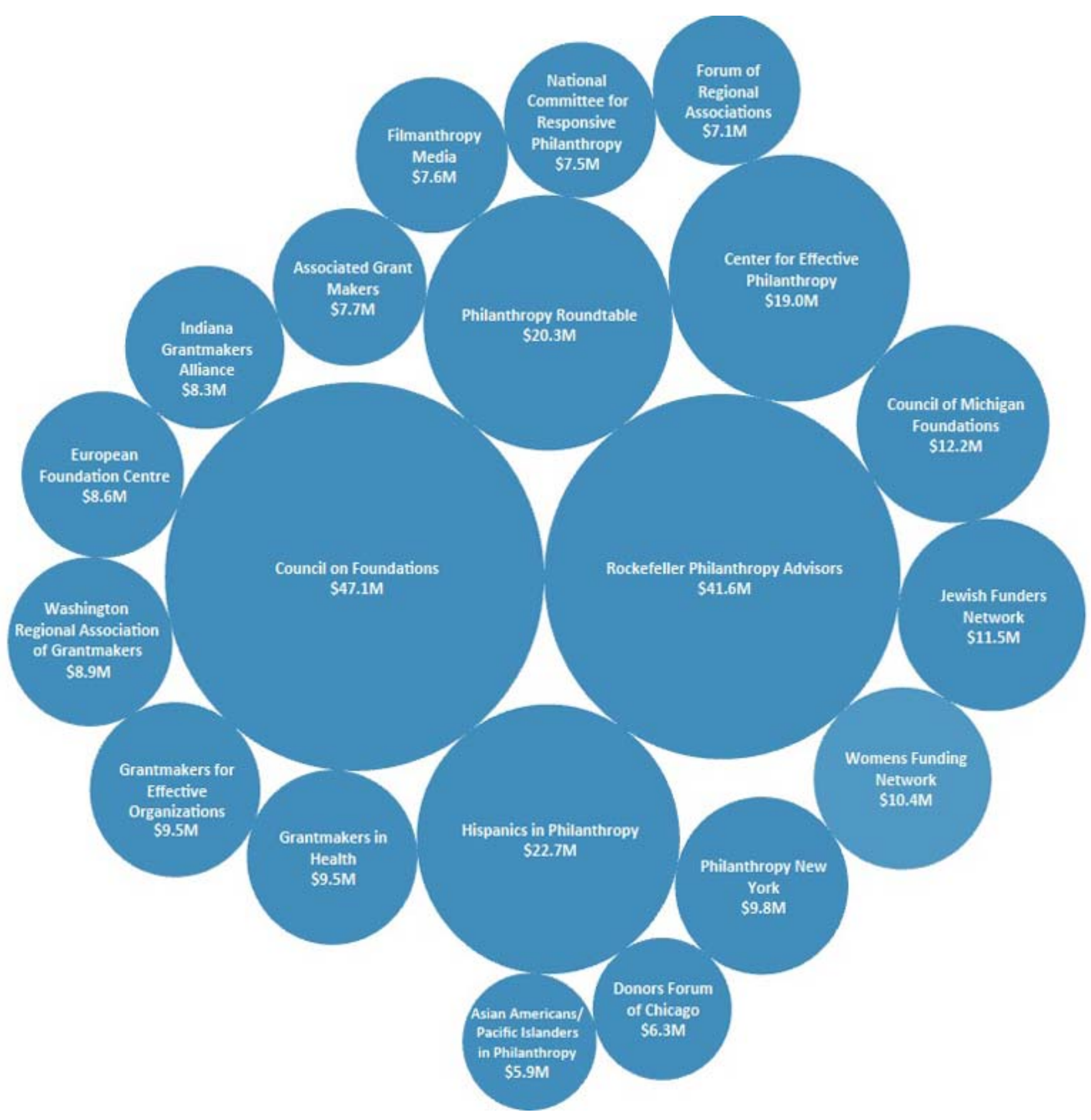

*Source: Foundation Center, 2015. Based on all grants of $\$ 10,000$ or more awarded by a national sample of larger U.S. foundations. 


\section{Which types of infrastructure organizations have benefitted from the most growth in funding?}

\section{Change in Funding for Other Nonprofit Infrastructure Organizations, Networks, and Services between 2004 and 2012*}

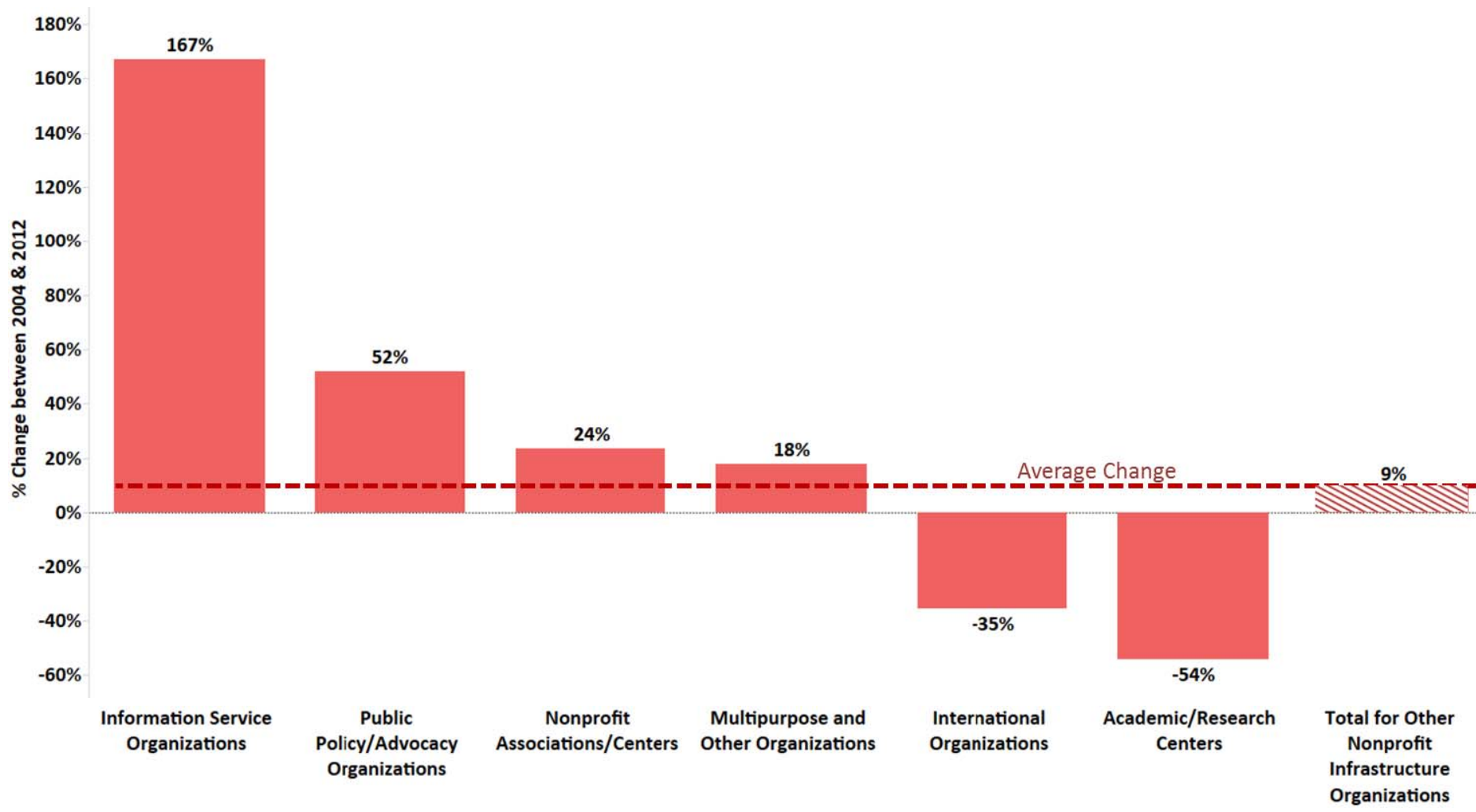

\section{KEY FINDINGS:}

- Information service organizations reported the largest growth in infrastructure funding by U.S. foundations between 2004 and 2012.

- In contrast, international organizations and academic/research centers experienced reductions in infrastructure funding during this period.

- Without further research, the exact causes of these reductions cannot be determined; but they may reflect pullbacks in infrastructure giving for these types of organizations and/or special projects as a result of the Great Recession.

- For examples of organizations in each category, see framework on page 5.

*Source: Foundation Center, 2015. Based on all grants of $\$ 10,000$ or more awarded by a national sample of larger U.S. foundations. 


\section{Top 20 Recipients: Other Nonprofit Infrastructure Organizations, Networks, and Services, 2004-2012*}

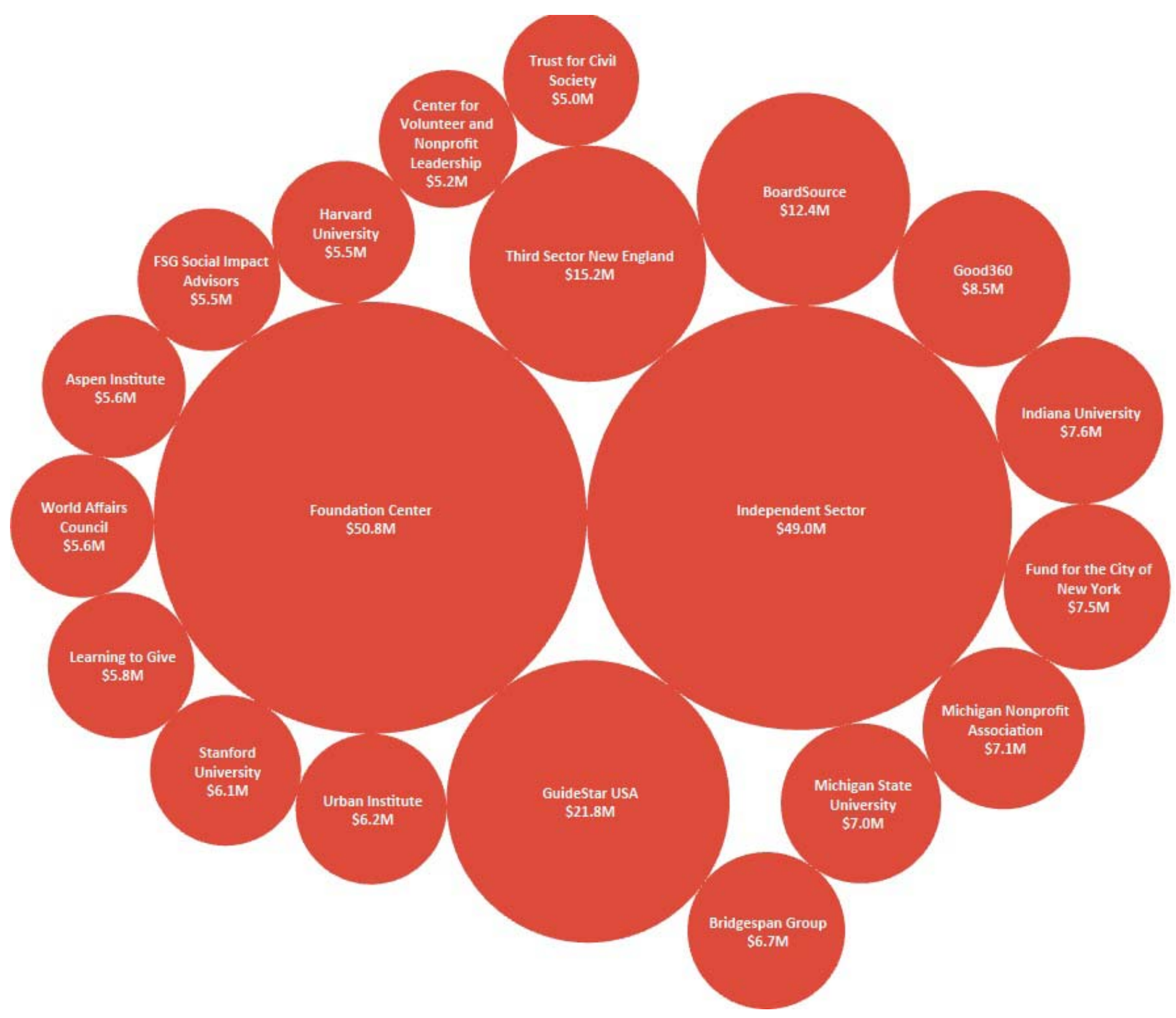

*Source: Foundation Center, 2015. Based on all grants of $\$ 10,000$ or more awarded by a national sample of larger U.S. foundations. 


\section{What share of funding provides membership or general/unrestricted support?}

\section{General Support/Membership as a Share of Overall Funding, 2004 and 2012*}

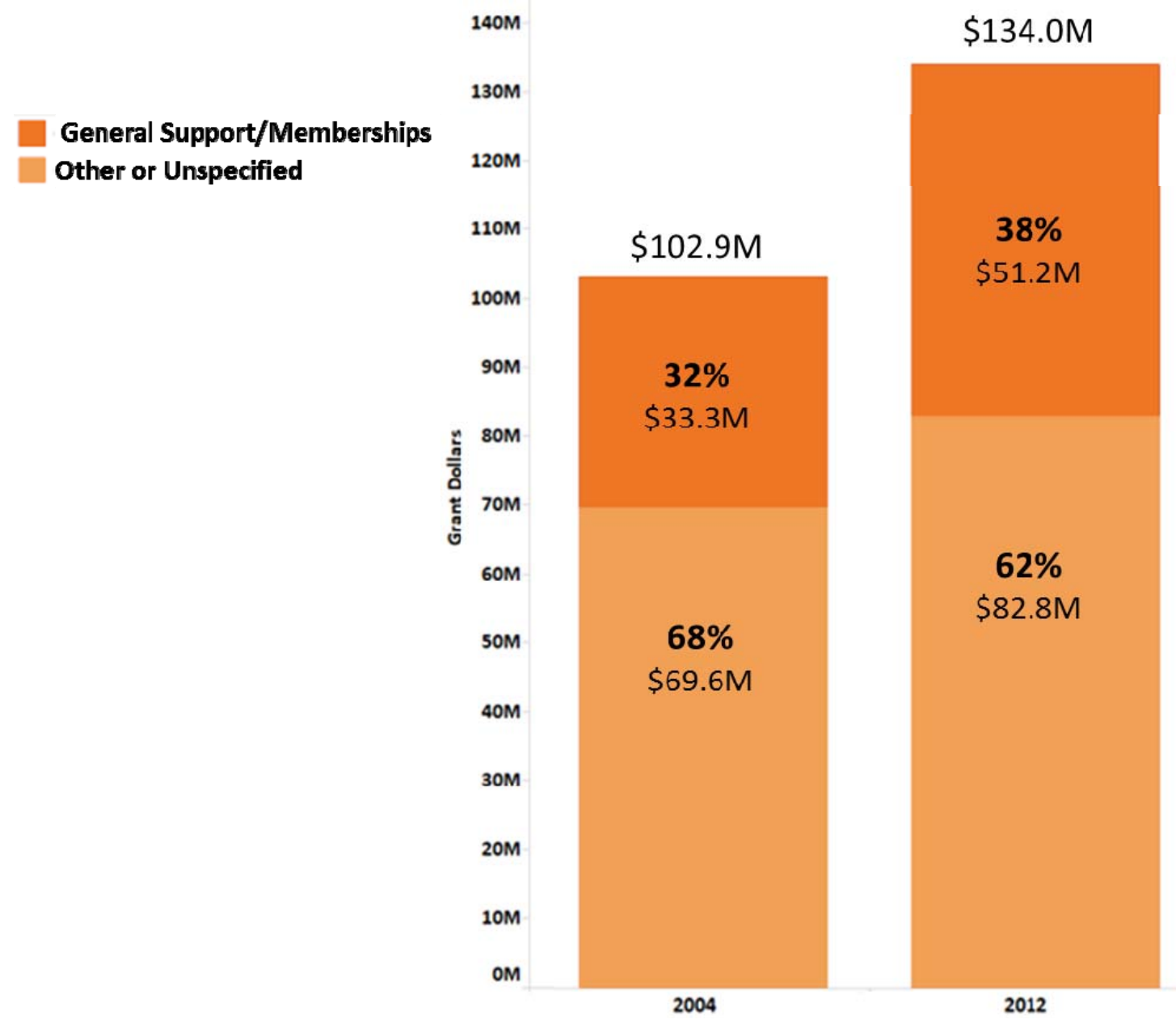

\section{KEY FINDINGS:}

- U.S. foundations providing support for nonprofit and philanthropic infrastructure directed a larger share of their giving for memberships and/or operating support in 2012 compared to 2004.

- This may reflect responsiveness to the calls by recipient organizations for more unrestricted funding.

*Source: Foundation Center, 2015. Based on all grants of $\$ 10,000$ or more awarded by a national sample of larger U.S. foundations. 
